\title{
Breast-feeding and growth in children until the age of 3 years: the Generation R Study
}

\author{
Büşra Durmuşs, ${ }^{1,3}$, Lenie van Rossem ${ }^{1,4}$, Liesbeth Duijts ${ }^{2,3}$, Lidia R. Arends ${ }^{5,6}$, Hein Raat ${ }^{4}$, \\ Henriëtte A. Moll ${ }^{2}$, Albert Hofman ${ }^{3}$, Eric A. P. Steegers ${ }^{7}$ and Vincent W. V. Jaddoe ${ }^{1,2,3 *}$ \\ ${ }^{1}$ The Generation R Study Group (AE-006), Erasmus Medical Center, PO Box 2040, 3000 CA, Rotterdam, The Netherlands \\ ${ }^{2}$ Department of Pediatrics, Erasmus Medical Center, PO Box 2040, 3000 CA, Rotterdam, The Netherlands \\ ${ }^{3}$ Department of Epidemiology, Erasmus Medical Center, PO Box 2040, 3000 CA, Rotterdam, The Netherlands \\ ${ }^{4}$ Department of Public Health, Erasmus Medical Center, PO Box 2040, 3000 CA, Rotterdam, The Netherlands \\ ${ }^{5}$ Institute of Psychology, Erasmus University, PO Box 1738, 3000 DR, Rotterdam, The Netherlands \\ ${ }^{6}$ Department of Biostatistics, Erasmus Medical Center, PO Box 2040, 3000 CA, Rotterdam, The Netherlands \\ ${ }^{7}$ Department of Obstetrics and Gynecology, Erasmus Medical Center, PO Box 2040, 3000 CA, Rotterdam, The Netherlands
}

(Received 31 March 2010 - Revised 25 November 2010 - Accepted 26 November 2010 - First published online 31 January 2011)

\begin{abstract}
Breast-feeding has been suggested to be associated with lower risks of obesity in older children and adults. We assessed whether the duration and exclusiveness of breast-feeding are associated with early postnatal growth rates and the risks of overweight and obesity in preschool children. The present study was embedded in a population-based prospective cohort study from early fetal life onwards, among 5047 children and their mothers in The Netherlands. Compared with children who were breast-fed, those who were never breast-fed had a lower weight at birth (difference 134 (95\% CI - 190, - 77) g). No associations between breast-feeding duration and exclusivity with growth rates before the age of 3 months were observed. Shorter breast-feeding duration was associated with an increased gain in age- and sex-adjusted standard deviation scores for length, weight and BMI $(P$ for trend $<0.05)$ between 3 and 6 months of age. Similar tendencies were observed for the associations of breast-feeding exclusivity with change in length, weight and BMI. Breast-feeding duration and exclusivity were not consistently associated with the risks of overweight and obesity at the ages of 1, 2 and 3 years. In conclusion, shorter breast-feeding duration and exclusivity during the first 6 months tended to be associated with increased growth rates for length, weight and BMI between the age of 3 and 6 months but not with the risks of overweight and obesity until the age of 3 years.
\end{abstract}

\section{Key words: Early feeding: Breast-feeding: Postnatal growth: Obesity}

Current recommendations advise initiation and continuation of breast-feeding for more than 6 months to promote child health ${ }^{(1-4)}$. Previous studies have suggested that breast-feeding has protective effects on the risks of CVD in adulthood ${ }^{(5,6)}$. Also, several studies have suggested that breast-feeding leads to a lower risk of obesity in later life $e^{(1-5)}$. These associations have been shown in several studies and meta-analyses, also after adjustment for several potential confounders ${ }^{(7)}$. Furthermore, a dose-dependent association has been shown, suggesting that a longer duration of breast-feeding is associated with a lower BMI in older children and adulthood $^{(8)}$.

Studies on the associations of breast-feeding with the risks of overweight and obesity in early childhood are scarce and have shown inconsistent results ${ }^{(9-11)}$. This inconsistency may be due to differences in study designs, indicators of overweight or obesity and assessment of breast-feeding ${ }^{(12)}$. Also, not all studies have data available about the exclusivity of breast-feeding. Assessing the associations of breast-feeding and childhood obesity at young ages is important since the risk of developing obesity may be partly explained by early postnatal growth patterns ${ }^{(12)}$. These growth patterns in early childhood might be intermediates in the associations of breast-feeding with obesity in later life ${ }^{(13)}$. Especially, high growth rates during the first months of life are associated with metabolic syndrome outcomes ${ }^{(14,15)}$.

We hypothesised that prolonged duration and exclusivity of breast-feeding lead to lower growth rates during the first year of life and subsequently to lower risks of overweight and obesity in preschool children. We examined, in a population-based prospective cohort study among 5047 children,

Abbreviation: SDS, standard deviation score.

*Corresponding author: Dr V. W. V. Jaddoe, email v.jaddoe@erasmusmc.nl 
the associations of breast-feeding duration and exclusivity with growth rates in infancy and the risks of overweight and obesity until the age of 3 years.

\section{Methods}

\section{Design}

The present study was embedded in the Generation R Study, a population-based prospective cohort study of pregnant women and their children from fetal life onwards in Rotterdam, The Netherlands ${ }^{(16,17)}$. Enrolment in the study was aimed at early pregnancy (gestational age $<18$ weeks) but was possible until birth of the child. Assessments during pregnancy included physical examinations, fetal ultrasound examinations and administration of questionnaires ${ }^{(17)}$. All children were born between April 2002 and January 2006 and form a prenatally enrolled birth cohort with a planned follow-up until young adulthood.

Postnatal growth data for the present study were available until the age of 3 years. Of all eligible children in the study area, $61 \%$ participated in the study at birth ${ }^{(17)}$. The present study was conducted according to the guidelines laid down in the Declaration of Helsinki, and all procedures involving human subjects were approved by the Medical Ethical Committee of the Erasmus Medical Center, Rotterdam, The Netherlands. Written informed consent was obtained from all participants.

\section{Duration and exclusiveness of breast-feeding}

Information about breast-feeding initiation and continuation was obtained from delivery reports and postal questionnaires at the ages of 2, 6 and 12 months after birth ${ }^{(17)}$. Mothers were asked whether they ever breast-fed their child (yes, no) and at what age they quitted breast-feeding. Subsequently, breastfeeding duration was categorised into four groups: (1) never; (2) less than 3 months; (3) 3-6 months; (4) 6 months or longer. Duration of exclusive breast-feeding was defined by using information about at what age other types of milk and/or solids were introduced in the first 6 months of life, according to a short FFQ. The information about duration and exclusiveness of breast-feeding was combined and categorised into the following three categories: (1) never; (2) partial breast-feeding until 4 months; (3) exclusive breast-feeding until 4 months. 'Never' indicates infants who were never breast-fed. 'Partial' indicates infants receiving breast-feeding, formula-feeding and/or solids in the first 4 months. 'Exclusive' indicates infants who have been breast-fed, without any other milk, solids or fluids during the first 4 months.

\section{Postnatal growth characteristics}

Postnatal growth was repeatedly measured at the community health centres according to a standard schedule and procedures by well-trained staff at the median ages of $3 \cdot 1$ months (95\% range $1 \cdot 1-4 \cdot 5), 6 \cdot 6$ months (95\% range $5 \cdot 2-$ 10.7), $13 \cdot 0$ months (95\% range 11.1-15.9), $24 \cdot 3$ months
(95\% range $18 \cdot 2-28 \cdot 3)$ and $36 \cdot 4$ months (95\% range $30 \cdot 4-$ 39.9). Length was measured in the supine position to the nearest millimetre until the age of 14 months using a neonatometer, after which height was measured in standing position by a Harpenden stadiometer (Holtain Limited, Crymych, Dyfed, UK). Weight was measured using a mechanical personal scale (SECA, Almere, The Netherlands). BMI $\left(\mathrm{kg} / \mathrm{m}^{2}\right)$ was calculated. Standard deviation scores (SDS) for postnatal growth characteristics were obtained using Dutch reference growth charts (Growth Analyzer 3.0; Dutch Growth Research Foundation, Rotterdam, The Netherlands). Relative overweight was defined as a BMI $>1 \cdot 1-2 \cdot 3$ SDS (approximate adult BMI of $25-30 \mathrm{~kg} / \mathrm{m}^{2}$ ), and obesity was defined as a BMI $>2 \cdot 3$ SDS (approximate adult BMI $>30)^{(18)}$. Growth rates were defined as the change in SDS in age intervals between $0-3,3-6$ and 6-12 months.

\section{Covariates}

Gestational age, sex and birth weight were obtained from midwife and hospital registries at birth. Information about highest attained maternal educational level (low, moderate and higher), maternal ethnicity (European, non-European) and parity (primiparity, multiparity) was obtained at enrolment in the study. Ethnicity and educational level of the parents were defined according to the classification of Statistics Netherlands ${ }^{(19,20)}$. Information on maternal smoking (yes, no) and alcohol consumption during pregnancy (yes, no) was retrieved from prenatal questionnaires. Maternal height and weight were measured at enrolment while the mother stood without shoes and heavy clothing, and BMI was calculated $\left(\mathrm{kg} / \mathrm{m}^{2}\right)$. Maternal age was registered at enrolment.

\section{Population for analysis}

In total, 7295 children and their parents participated in the postnatal phase of the study and gave consent for participating in the questionnaire studies (Fig. 1). Children without complete information on breast-feeding and twins were excluded from the analyses. Of the remaining singleton live births with complete data on breast-feeding, information about postnatal growth characteristics that measures at least one age was available in 5074 children.

\section{Statistical analysis}

Differences in baseline characteristics between the breastfeeding duration categories were compared with ANOVA for continuous variables and $\chi^{2}$ tests for categorical variables. The associations of breast-feeding (never, ever), breast-feeding duration (never, 0-3, 3-6 and 6-12 months) and breastfeeding exclusivity (never, partial until 4 months and exclusive until 4 months) with the change in postnatal growth characteristics (length, weight and BMI) in SDS for different age periods (0-3, 3-6 and 6-12 months) were assessed using multiple linear regression models. Both dependent and independent variables were quantitative, and categorical variables were recoded to binary variables. The models were adjusted for 


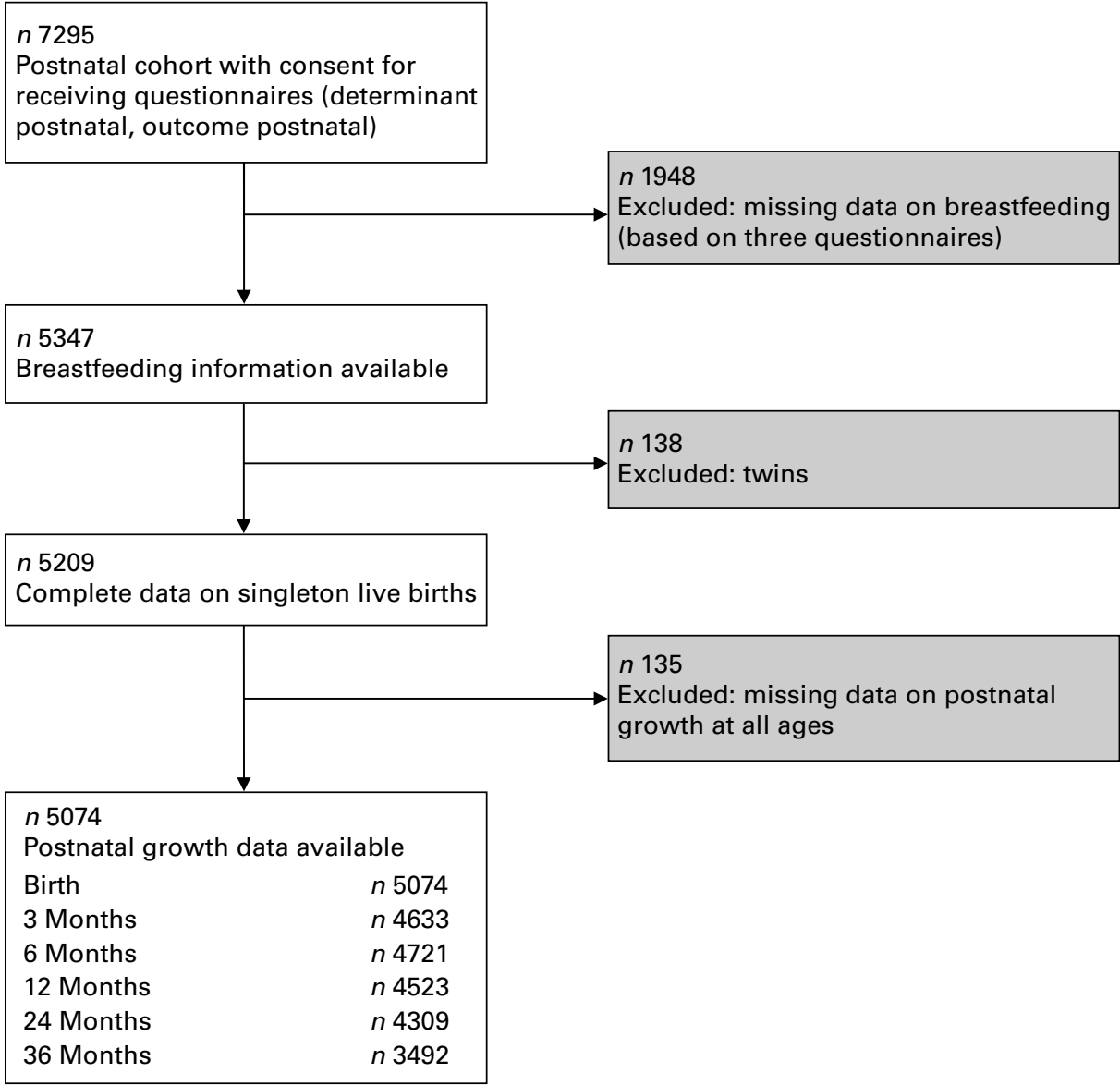

Fig. 1. Flow chart of participants in the study.

potential confounders including child's age at visit, sex, birth weight, gestational age, maternal ethnicity, maternal education, maternal BMI, parity and smoking. Gestational age at enrolment was not included in the models since it did not materially change the results. Confounders were included in the models based on the literature or a change in effect estimates of more than $10 \%$. We used the 'enter' method for including and excluding the independent variables.

For the analyses focused on the associations of breastfeeding duration with growth characteristics until the age of 3 months, we combined the breast-feeding groups into never and ever $(0-3,3-6$ and $>6$ months). For the analyses focused on growth characteristics at the age of 3-6 months, we combined the breast-feeding duration groups into never, $0-3$ and 3-6 months (3-6 and >6 months). Furthermore, we examined the associations of breast-feeding duration and exclusivity with differences in BMI at the ages of 1,2 and 3 years, and the risks of overweight and obesity at the same ages, using linear regression and logistic regression models, respectively. Finally, we assessed the associations of breast-feeding duration and exclusivity with longitudinally measured SDS of BMI in terms of overweight or obesity (combined outcome BMI $>1 \cdot 1$ SDS) using the generalised estimating equation, taking into account correlations within subjects and assessing both time-dependent and -independent associations.
Tests for trends were performed by treating each categorised variable as a continuous term and by entering the variable into the fully adjusted linear regression model. To handle missing values in covariates, we performed multiple imputations by generating five independent datasets for all analyses. For the generalised estimating equation analyses, we performed multiple imputations of the data using Proc MI and Proc MIAnalyze. Imputations were based on the relationships between all covariates included in the present study. All measures of association are presented with their 95\% CI. Cross-sectional analyses were performed using the Statistical Package of Social Sciences version 17.0 for Windows (SPSS, Inc., Chicago, IL, USA). The generalised estimating equations analysis, including the Prox Genmod module, was performed with the Statistical Analysis System (version 9.1; SAS Institute, Inc., Cary, NC, USA).

\section{Results}

Of the total group of 5074 children, $89 \cdot 8 \%$ had ever been breast-fed (Table 1). Compared with mothers who breast-fed their children for more than 6 months, those who never breast-fed their children tended to have a younger age, higher BMI, higher rate of obesity, lower educational level, Dutch or European background and were more likely to smoke during pregnancy. Also, children who were never 
Table 1. Subject characteristics according to the duration of breast-feedingt

(Mean values, standard deviations, percentages or medians (90\% ranges) for variables with a skewed distribution, $n$ 5074)

\begin{tabular}{|c|c|c|c|c|c|}
\hline & Total & Never breast-fed & $0-3$ months & $3-6$ months & $>6$ months \\
\hline \multicolumn{6}{|l|}{ Maternal characteristics } \\
\hline \multicolumn{6}{|l|}{ Age (years) } \\
\hline Median & $30 \cdot 9$ & $30 \cdot 6$ & $29 \cdot 9^{\star *}$ & $31 \cdot 5^{\star \star}$ & $32 \cdot 1^{\star \star}$ \\
\hline $90 \%$ Range & $21 \cdot 9-38.5$ & $21 \cdot 3-38 \cdot 5$ & $20 \cdot 9-37 \cdot 8$ & $23 \cdot 0-38 \cdot 3$ & $24 \cdot 2-39 \cdot 2$ \\
\hline \multicolumn{6}{|l|}{ Gestational weight change/week (kg) } \\
\hline Mean & 0.45 & 0.45 & 0.44 & 0.45 & 0.45 \\
\hline SD & 0.2 & 0.2 & 0.2 & 0.2 & 0.2 \\
\hline \multicolumn{6}{|l|}{ Height $(\mathrm{cm})$} \\
\hline Mean & $168 \cdot 2$ & $168 \cdot 3$ & $167 \cdot 6$ & 168.9 & $168 \cdot 7$ \\
\hline SD & $7 \cdot 3$ & 6.9 & 7.4 & $7 \cdot 1$ & $7 \cdot 3$ \\
\hline \multicolumn{6}{|l|}{ Weight (kg) } \\
\hline Mean & 69.5 & $72 \cdot 1$ & $70 \cdot 2^{*}$ & $68 \cdot 9^{* *}$ & $68 \cdot 1^{\star *}$ \\
\hline SD & $12 \cdot 8$ & $15 \cdot 4$ & $13 \cdot 7$ & 11.4 & $11 \cdot 2$ \\
\hline \multicolumn{6}{|l|}{ BMI $\left(\mathrm{kg} / \mathrm{m}^{2}\right)$} \\
\hline Mean & $24 \cdot 6$ & $25 \cdot 4$ & $25 \cdot 0$ & $24 \cdot 2^{\star *}$ & $23 \cdot 9^{\star *}$ \\
\hline SD & $4 \cdot 3$ & $5 \cdot 0$ & 4.8 & $3 \cdot 8$ & 3.7 \\
\hline Overweight (\%)† & $23 \cdot 0$ & $26 \cdot 7$ & $27 \cdot 2$ & $24 \cdot 1$ & $23 \cdot 8$ \\
\hline Obesity (\%)† & $11 \cdot 0$ & $17 \cdot 1$ & 13.9 & $8 \cdot 7^{\star *}$ & $6 \cdot 8^{\star *}$ \\
\hline \multicolumn{6}{|l|}{ Highest educational level (\%) } \\
\hline Low & 7.5 & 7.4 & $9 \cdot 4^{\star *}$ & $3 \cdot 8^{\star \star}$ & $6 \cdot 0^{\star *}$ \\
\hline Moderate & $41 \cdot 1$ & $62 \cdot 4$ & $50 \cdot 0^{\star *}$ & $33 \cdot 3^{\star \star}$ & $26 \cdot 5^{\star \star}$ \\
\hline Higher & 51.4 & $30 \cdot 2$ & $40 \cdot 6^{\star \star}$ & $62 \cdot 9^{\star \star}$ & $67 \cdot 5^{\star \star}$ \\
\hline \multicolumn{6}{|l|}{ Ethnicity (\%) } \\
\hline Dutch and other Europeans & $67 \cdot 6$ & $79 \cdot 7$ & $62 \cdot 2^{\star *}$ & $71 \cdot 6^{\star *}$ & $71 \cdot 1^{* *}$ \\
\hline Non-European & $32 \cdot 4$ & $20 \cdot 3$ & $37 \cdot 8^{\star \star}$ & $28 \cdot 4^{\star *}$ & $28 \cdot 9^{\star *}$ \\
\hline \multicolumn{6}{|l|}{ Smoking during pregnancy (\%) } \\
\hline Ever & $25 \cdot 4$ & $40 \cdot 1$ & $31 \cdot 1^{\star \star}$ & $20 \cdot 3^{\star \star}$ & $17 \cdot 1^{\star \star}$ \\
\hline Never & $74 \cdot 6$ & $59 \cdot 9$ & $68 \cdot 9^{\star \star}$ & $79 \cdot 7^{\star \star}$ & $82 \cdot 9^{\star *}$ \\
\hline \multicolumn{6}{|c|}{ Alcohol consumption during pregnancy (\%) } \\
\hline Ever & $59 \cdot 9$ & $49 \cdot 2$ & $55 \cdot 7$ & $69 \cdot 2^{\star \star}$ & $63 \cdot 8^{\star \star}$ \\
\hline Never & $40 \cdot 1$ & $50 \cdot 8$ & $44 \cdot 3$ & $30 \cdot 8^{\star \star}$ & $36 \cdot 2^{\star *}$ \\
\hline \multicolumn{6}{|l|}{ Parity (\%) } \\
\hline 0 & 57.5 & $47 \cdot 3$ & $62 \cdot 0^{\star \star}$ & $60 \cdot 1^{\star \star}$ & $53 \cdot 8^{*}$ \\
\hline$\geq 1$ & $42 \cdot 5$ & $52 \cdot 7$ & $38 \cdot 0^{\star *}$ & $39 \cdot 9^{* *}$ & $46 \cdot 2^{*}$ \\
\hline \multicolumn{6}{|l|}{ Birth characteristics } \\
\hline Males (\%) & 50 & 52 & 50 & 50 & 47 \\
\hline \multicolumn{6}{|l|}{ Gestational age (weeks) } \\
\hline Median & 39.9 & $39 \cdot 7$ & 39.9 & $39 \cdot 9^{\star}$ & $40 \cdot 1^{\star \star}$ \\
\hline $90 \%$ Range & $37 \cdot 1-42 \cdot 1$ & $37 \cdot 0-42 \cdot 0$ & $36 \cdot 9-42 \cdot 0$ & $37 \cdot 1-42 \cdot 1$ & $37 \cdot 7-42 \cdot 1$ \\
\hline \multicolumn{6}{|l|}{ Weight (g) } \\
\hline Mean & 3449 & 3391 & 3409 & $3456^{\star}$ & $3525^{\star \star}$ \\
\hline SD & 546 & 582 & 548 & 554 & 506 \\
\hline Small-for-gestational age $(<5 \%) \dagger$ & $5 \cdot 0$ & 6.5 & $5 \cdot 8$ & $5 \cdot 0$ & $3 \cdot 9^{*}$ \\
\hline Low birth weight $(<2500 \mathrm{~g}) \%$ & $4 \cdot 1$ & $5 \cdot 8$ & $5 \cdot 2$ & $4 \cdot 1$ & $2 \cdot 0^{\star \star}$ \\
\hline Pre-term birth (\%) & $4 \cdot 8$ & $5 \cdot 6$ & 5.5 & 4.6 & $3 \cdot 4^{\star}$ \\
\hline
\end{tabular}

Differences in maternal and child characteristics for the breast-feeding duration groups were evaluated using ANOVA for continuous variables and $\chi^{2}$ tests for categorical variables: ${ }^{\star} P<0.05,{ }^{* \star} P<0.01$.

† Overweight is defined as BMI $>25-29.9 \mathrm{~kg} / \mathrm{m}^{2}$. Obesity is defined as BMI $>30 \mathrm{~kg} / \mathrm{m}^{2}$. Small-for-gestational age is defined as the lowest $5 \%$ of gestational age-adjusted birth weight.

breast-fed had a lower weight at birth and a higher prevalence of small size for gestational age and pre-term birth (all $P<0.05)$. The median duration of breast-feeding was 4.4 (95\% range $0.5-12 \cdot 0)$ months. In total, $65.7 \%$ of all children were breast-fed partially until the age of 4 months, and $24 \cdot 1 \%$ of all children were breast-fed exclusively until the age of 4 months.

Table 2 shows the associations of breast-feeding, breastfeeding duration and exclusivity with postnatal growth rates (length, weight and BMI) in different time periods presented as changes in SDS. Breast-feeding duration and exclusivity were not associated with growth rates before the age of 3 months. Compared with children who were ever breast-fed, those who never breast-fed had a higher gain in length and weight between the age of 3 and 6 months (difference 0.07 (95\% CI 0.01, 0.14) SDS) and (0.06 (95\% CI 0.01, 0.12) SDS), respectively. Compared with children who were breast-fed for more than 3 months, children who were breast-fed shorter than 3 months also had a higher gain in length and weight between the ages of 3 and 6 months (all $P$ for trend <0.01). The highest gain in length was observed in children who were breast-fed for only 0-3 months. We observed similar tendencies for the associations between breast-feeding exclusivity and gain in length, weight and BMI between the age of 3 and 6 months. Children who were never breast-fed or breast-fed partially until 4 months showed a higher increase in length, 
WS British Journal of Nutrition

Table 2. Breast-feeding duration and exclusivity and growth rates in different intervals during the first year of infancy $\dagger$

(Regression coefficients and $95 \%$ confidence intervals, $n$ 5074)

\begin{tabular}{|c|c|c|c|c|c|c|c|c|}
\hline & \multicolumn{3}{|c|}{ Length (change in SDS) } & \multicolumn{3}{|c|}{ Weight (change in SDS) } & \multicolumn{2}{|c|}{ BMI (change in SDS) } \\
\hline & $0-3$ months & $3-6$ months & $6-12$ months & $0-3$ months & $3-6$ months & $6-12$ months & $3-6$ months & $6-12$ months \\
\hline $\begin{array}{l}\text { Ever breast-feeding }(n) \\
\quad \text { Never }(n 516)\end{array}$ & 2983 & \multicolumn{7}{|c|}{ Never $(n 516)$} \\
\hline Regression coefficient & -0.01 & $0.07^{\star}$ & -0.03 & 0.01 & $0.06^{\star}$ & -0.03 & 0.02 & -0.03 \\
\hline $95 \% \mathrm{Cl}$ & $-0.14,0.12$ & $0.01,0.14$ & $-0.09,0.03$ & $-0.08,0.09$ & $0.01,0.12$ & $-0.09,0.03$ & $-0.06,0.11$ & $-0.11,0.06$ \\
\hline$n$ & 309 & 417 & 420 & 419 & 434 & 426 & 414 & 414 \\
\hline \multicolumn{9}{|l|}{ Ever ( $n$ 4555) } \\
\hline $\begin{array}{l}\text { Regression coefficient } \\
95 \% \mathrm{Cl}\end{array}$ & Reference & Reference & Reference & Reference & Reference & Reference & Reference & Reference \\
\hline$n$ & 2674 & 3795 & 3771 & 3952 & 4025 & 3857 & 3789 & 3753 \\
\hline Duration $(n)$ & 2709 & 3804 & 3776 & 3942 & 4027 & 3859 & 3795 & 3755 \\
\hline \multicolumn{9}{|l|}{ Never $(n 516)$} \\
\hline Regression coefficient & -0.02 & $0 \cdot 17^{* *}$ & -0.04 & 0.01 & $0 \cdot 14^{\star \star}$ & -0.03 & 0.03 & -0.01 \\
\hline $95 \% \mathrm{Cl}$ & $-0.15,0.12$ & $0.10,0.24$ & $-0.11,0.03$ & $-0.08,0.09$ & $0.08,0.20$ & $-0.10,0.03$ & $-0.06,0.12$ & $-0.10,0.08$ \\
\hline$n$ & 310 & 418 & 421 & 420 & 435 & 427 & 415 & 415 \\
\hline \multicolumn{9}{|l|}{$0-3$ months ( $n$ 1832) } \\
\hline Regression coefficient & & $0 \cdot 19^{\star *}$ & -0.03 & & $0.14^{\star \star}$ & -0.01 & 0.02 & 0.02 \\
\hline $95 \% \mathrm{Cl}$ & Reference & $0.15,0.24$ & $-0.08,0.02$ & Reference & $0 \cdot 10,0 \cdot 18$ & $-0.05,0.04$ & $-0.03,0.08$ & $-0.04,0.08$ \\
\hline$n$ & 2399 & 1522 & 1497 & 3522 & 1615 & 1528 & 1518 & 1488 \\
\hline \multicolumn{9}{|l|}{$3-6$ months ( $n$ 1039) } \\
\hline $\begin{array}{l}\text { Regression coefficient } \\
95 \% \mathrm{Cl}\end{array}$ & & Reference & $\begin{array}{c}0.01 \\
-0.05,0.06\end{array}$ & & Reference & $\begin{array}{c}0.02 \\
-0.03,0.07\end{array}$ & Reference & $\begin{array}{c}0.03 \\
-0.04,0.10\end{array}$ \\
\hline$n$ & NA & 1864 & 892 & NA & 1977 & 912 & 1862 & 889 \\
\hline \multicolumn{9}{|l|}{$>6$ months $(n 1149)$} \\
\hline $\begin{array}{l}\text { Regression coefficient } \\
95 \% \mathrm{Cl}\end{array}$ & & & Reference & & & Reference & & Reference \\
\hline$n$ & NA & NA & 966 & NA & NA & 992 & NA & 963 \\
\hline$P$ for trend & 0.48 & $<0.01$ & 0.15 & 0.98 & $<0.01$ & 0.28 & 0.03 & 0.96 \\
\hline Exclusive breast-feeding $(n)$ & 2986 & 4216 & 4195 & 4375 & 4463 & 4287 & 4207 & 4171 \\
\hline \multicolumn{9}{|l|}{ Never $(n 516)$} \\
\hline Regression coefficient & -0.05 & $0.24^{\star \star}$ & -0.05 & 0.01 & $0.22^{\star \star}$ & -0.02 & 0.09 & 0.01 \\
\hline $95 \% \mathrm{Cl}$ & $-0.20,0.10$ & $0.17,0.32$ & $-0.12,0.02$ & $-0.09,0.11$ & $0.16,0.29$ & $-0.08,0.05$ & $-0.01,0.18$ & $-0.08,0.10$ \\
\hline$n$ & 310 & 418 & 421 & 420 & 435 & 427 & 415 & 415 \\
\hline \multicolumn{9}{|c|}{ Partial until 4 months ( $n 3333)$} \\
\hline Regression coefficient & -0.05 & $0.23^{\star *}$ & -0.02 & 0.01 & $0.21^{\star \star}$ & 0.02 & $0.08^{\star *}$ & 0.05 \\
\hline $95 \% \mathrm{Cl}$ & $-0.15,0.04$ & $0.18,0.27$ & $-0.07,0.02$ & $-0.05,0.07$ & $0.17,0.25$ & $-0.02,0.06$ & $0.02,0.14$ & $-0.01,0.11$ \\
\hline$n$ & 1898 & 2745 & 2741 & 2875 & 2471 & 2806 & 2738 & 2726 \\
\hline \multicolumn{9}{|c|}{ Exclusive until 4 months ( $n$ 1225) } \\
\hline $\begin{array}{l}\text { Regression coefficient } \\
95 \% \mathrm{Cl}\end{array}$ & Reference & Reference & Reference & Reference & Reference & Reference & Reference & Reference \\
\hline$n$ & 778 & 1053 & 1033 & 1080 & 933 & 1045 & 1045 & 1030 \\
\hline$P$ for trend & 0.33 & $<0.01$ & 0.17 & 0.82 & $<0.01$ & 0.96 & 0.01 & 0.37 \\
\hline
\end{tabular}

SDS, standard deviation score; NA, not applicable.

Using multiple linear regression models: ${ }^{*} P<0.05,{ }^{\star *} P<0.01$

† Models are adjusted for child's age at visit, sex, birth weight, gestational age, maternal ethnicity, maternal education, maternal BMI, smoking and parity. For the analyses focused on growth characteristics at the age of $0-3$ months, we combined the breast-feeding duration groups into never and ever (0-3, 3-6 and >6 months). For the analyses focused on growth characteristics at the age of 3-6 months, we combined the breast-feeding duration groups into never, $0-3$ months and 3-6 months (3-6 and $>6$ months). 
weight and BMI. The highest effects were observed for children who were never breast-fed. Breast-feeding duration and exclusivity were not associated with growth between the age of 6 and 12 months.

Fig. 2 shows the results from the longitudinal generalised estimating equation models, which indicates no consistent associations between breast-feeding duration and exclusivity with the risks of overweight and obesity (BMI $>1 \cdot 1$ SDS) at the ages of 1, 2 and 3 years. In addition, there was no consistent association between breast-feeding duration and exclusivity with BMI, overweight or obesity (see Table S1 of the supplementary material available at http://www.journals. cambridge.org/bjn).

\section{Discussion}

\section{Main findings}

Breast-feeding duration and exclusivity were inversely associated with growth rates in length, weight and BMI between the ages of 3 and 6 months. We did not observe associations between breast-feeding duration and exclusivity and the risks of overweight and obese in the first 3 years of life.

\section{Strengths and weaknesses}

An important strength of the present study was the populationbased cohort, with a large number of subjects being studied from early pregnancy onwards and information about a large number of potential confounders available. Information was

(a)

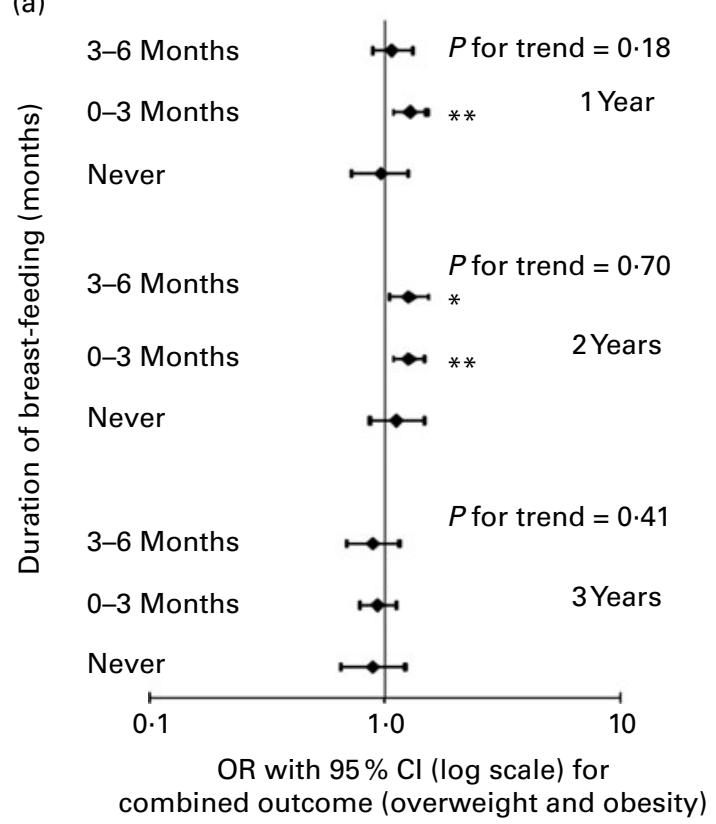

available about duration and exclusivity of breast-feeding. Some methodological issues need to be considered. Of all children in the present study, questionnaires with breastfeeding information were available in $68 \%$. This non-response would lead to biased effect estimates if the associations of breast-feeding duration and exclusivity with postnatal growth characteristics would be different between those included and not included in the analyses. However, this seems unlikely because biased estimates in large cohort studies mainly arise from loss to follow-up rather than from nonresponse at baseline ${ }^{(21)}$. In the present analysis, loss to follow-up was $<10 \%$. However, the number of follow-up measurements was smaller with increasing age. Information about breast-feeding was prospectively collected by questionnaires without direct reference to any growth characteristic. Although assessing breast-feeding by questionnaires seems to be a valid method, misclassification may occur ${ }^{(22,23)}$. We estimated breast-feeding exclusivity according to whether the child received breast-feeding without any other infant formula, milk or solids according to the short FFQ. This definition does not cover the strict criteria used by the WHO, which suggest that even the use of water in combination with breast-feeding does not fulfil the definition of exclusivity. However, we did ask for the most commonly introduced solids and fluids. Furthermore, in The Netherlands, it is not common that children receive breast-feeding in combination with the use of water to prevent dehydration. Therefore, we think that our measurement of exclusive breast-feeding is a good proxy for exclusive breast-feeding according to the WHO criteria.

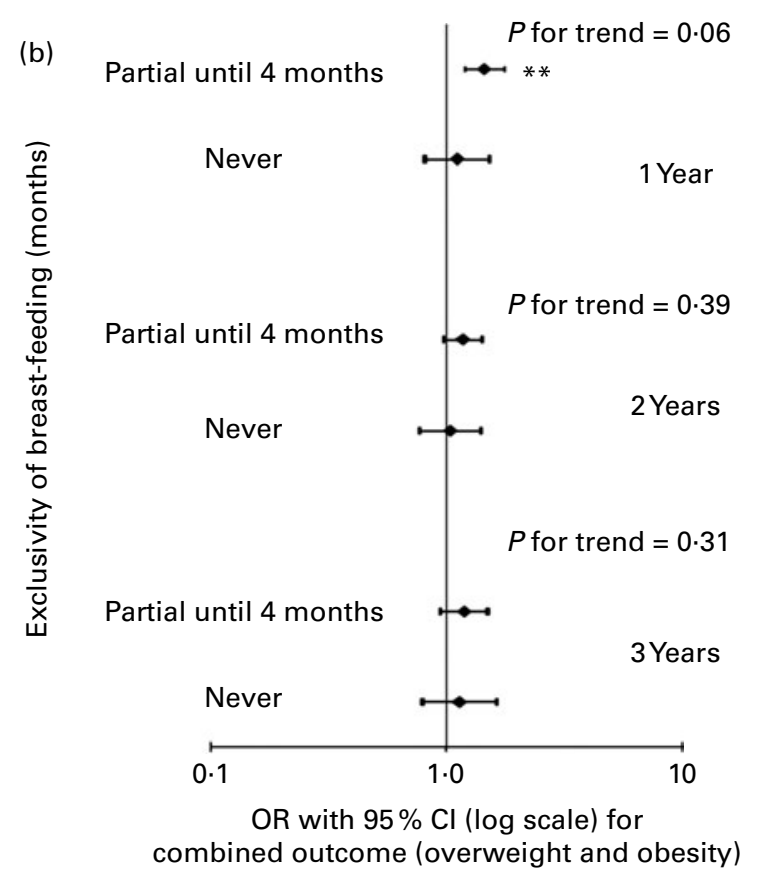

Fig. 2. Breastfeeding and the risks of overweight and obesity in the first 3 years. (a) Breastfeeding duration. (b) Breastfeeding exclusivity. Values are OR with $95 \% \mathrm{Cl}$ represented by horizontal bars. Breastfeeding duration for more than 6 months and breastfeeding exclusivity until 4 months, are considered as the reference groups in (a) and (b), respectively. Using generalised estimating equations: ${ }^{\star} P<0.05,{ }^{\star *} P<0.01$. Models are adjusted for child's age at visit, sex, birth weight, gestational age, maternal ethnicity, maternal education, maternal BMI, smoking and parity. Outcome is defined as age- and sex-adjusted BMI $>1 \cdot 1$ standard deviation scores. 
Finally, we used BMI for defining overweight and obesity in early childhood. We should be careful with these definitions, as at this young age there is no clear cut-off point to define obesity, and BMI cannot differentiate between fat and lean mass.

\section{Comparison of main findings with other studies}

In line with previous studies ${ }^{(24-26)}$, we observed differences in maternal characteristics between breast-feeding duration groups. We previously showed socio-economic and ethnic differences in breast-feeding duration ${ }^{(27,28)}$. In the present study group, mothers who never breast-fed their children were also more likely to have a younger age, higher BMI, Dutch or European background and were more likely to smoke during pregnancy. We additionally observed that children who were never breast-fed had a lower weight at birth and a higher risk of small size for gestational age and preterm birth. The associations of maternal and birth characteristics with breast-feeding initiation and duration show that these characteristics should be considered as potential confounders when studying the associations between breast-feeding and childhood growth.

It has been shown that after the first week of life, growth patterns appear to be similar between breast-fed and formula-fed children for the first $2-3$ months $^{(29)}$. However, thereafter, the growth rates between breast-fed and formulafed children diverge with less distinct differences in length gain than in weight gain. Previous studies have suggested that breast-fed children have a slower growth between 3 and 12 months of life $\mathrm{e}^{(30-33)}$. The present results are in line with the findings, but we showed that children who were never breast-fed have higher growth rates in length and weight only between the ages of 3 and 6 months. After the age of 6 months, it is very likely that complementary foods such as fruit and vegetable snacks are introduced. This may explain why we did not observe any effects in growth after the age of 6 months. We also showed that exclusive breast-feeding for 4 months was associated with a lower gain in length, weight and BMI during the first 3-6 months. This is in line with a previous study in randomly selected healthy newborns from Denmark and Iceland, which showed that exclusive breast-feeding influenced growth rates during infancy ${ }^{(33)}$. The authors suggested that exclusive breast-feeding until 2 months is related to lower weight gain from 2 to 6 months as well as from 6 to 12 months.

The biological mechanisms by which breast-feeding might protect against high growth rates are not well understood. One suggested mechanism is that high protein intake in formula-feeding stimulates the secretion of insulin-like growth factor I, which accelerates growth and increases muscle mass and adipose tissue ${ }^{(34)}$. Prolonged breast-feeding duration might also reduce plasma levels of appetite-related peptide and ghrelin ${ }^{(34,35)}$. Furthermore, formula-fed infants have higher plasma insulin concentrations, which might result in increased insulin resistance ${ }^{(35)}$.

Studies that focused on the associations between breastfeeding and the risk of overweight and obesity in early childhood have shown inconsistent results ${ }^{(9-11)}$. In the present study, breast-feeding duration and exclusivity were not consistently associated with the risk of overweight and obesity in the first 3 years of life. We observed that partial feeding until 4 months may increase the risk of overweight and obesity. However, this association was not consistent with the other results. We cannot explain this specific association, which might also be a chance finding.

Similar results in this age range have been observed in previous studies ${ }^{(36-38)}$. Furthermore, high postnatal growth rates in the first 6 months of life are independently associated with the risks of overweight and obesity in later life ${ }^{(39)}$. Therefore, the associations between shorter duration of breast-feeding and the risks of overweight and obesity might appear at older ages.

\section{Conclusion}

The present results suggest that shorter breast-feeding duration and exclusivity are associated with increased postnatal growth rates for height, weight and body mass in the first 3-6 months of life. Breast-feeding duration and exclusivity are not associated with the risks of overweight and obesity in the first 3 years. Further research is needed to assess whether and from which age breast-feeding duration and exclusiveness are associated with childhood obesity.

\section{Acknowledgements}

The Generation R Study is conducted by the Erasmus Medical Center in close collaboration with the School of Law and Faculty of Social Sciences of the Erasmus University Rotterdam, Rotterdam, The Netherlands; the Municipal Health Service Rotterdam area, Rotterdam, The Netherlands; the Rotterdam Homecare Foundation, Rotterdam, The Netherlands; the Stichting Trombosedienst and Artsenlaboratorium Rijnmond, Rotterdam, The Netherlands. We gratefully acknowledge the contribution of participating mothers, general practitioners, hospitals, midwives and pharmacies in Rotterdam. The first phase of the Generation R Study is made possible by financial support from the Erasmus Medical Center, Rotterdam, The Netherlands; the Erasmus University Rotterdam, Rotterdam, The Netherlands; the Netherlands Organization for Health Research, The Hague, The Netherlands. V. W. V. J. reports receipt of additional funding from the Netherlands Organization for Health Research and Development (ZonMw 90700303). The authors declare that there is no conflict of interest. The authors' contributions are as follows: B. D. and V. W. V. J. had a role in conception and design, performed the statistical analysis and wrote the manuscript. L. v. R., L. D., L. R. A., H. R., H. A. M., A. H. and E. A. P. S. provided comments and consultation regarding the analyses and the manuscript. All authors gave final approval of the version to be published.

\section{References}

1. Gartner LM, Morton J, Lawrence RA, et al. (2005) Breastfeeding and the use of human milk. Pediatrics 115, 496-506. 
2. Office of Women's Health. US Department of Health and Human Services 2006 (2006) Breast feeding. http://www. womenshealth.gov/breastfeeding/index.cfm?page_Campaign (last accessed 17 October 2009).

3. U.S. Preventive Services Task Force (2008) Primary care interventions to promote breastfeeding: U.S. Preventive Services Task Force recommendation statement. Ann Intern Med 149, 560-564.

4. World Health Organization \& Department of Nutrition for Health and Development (2001) The Optimal Duration of Exclusive Breastfeeding: Report of an Expert Consultation. Geneva: World Health Organization.

5. Martin RM, Ben Shlomo Y, Gunnell D, et al. (2005) Breast feeding and cardiovascular disease risk factors, incidence, and mortality: the Caerphilly study. J Epidemiol Community Health 59, 121-129.

6. Ravelli AC, van der Meulen JH, Osmond C, et al. (2000) Infant feeding and adult glucose tolerance, lipid profile, blood pressure, and obesity. Arch Dis Child 82, 248-252.

7. Owen CG, Martin RM, Whincup PH, et al. (2005) The effect of infant feeding on the risk of obesity across the life course: a quantitative review of published evidence. Pediatrics $\mathbf{1 1 5}$, 1367-1377.

8. Harder T, Bergmann R, Kallischnigg G, et al. (2005) Duration of breastfeeding and risk of overweight: a meta-analysis. Am J Epidemiol 163, 397-403.

9. Beyerlein A, Fahrmeir L, Mansmann U, et al. (2008) Alternative regression models to assess increase in childhood BMI. BMC Med Res Methodol 8, 1-9.

10. Zive MM, McKay H, Frank-Spohrer GC, et al. (1992) Infant-feeding practices and adiposity in 4-y-old Angloand Mexican-Americans. Am J Clin Nutr 55, 1104-1108.

11. Agras WS, Kraemer HC, Berkowitz RI, et al. (1990) Influence of early feeding style on adiposity at 6 years of age. $J$ Pediatr 116, 805-809.

12. Anderson AK (2009) Association between Infant Feeding and Early Postpartum Infant Body Composition: A Pilot Prospective Study. Int J Pediatr 2009, 648091.

13. Stettler N, Stallings VA, Troxel AB, et al. (2005) Weight gain in the first week of life and overweight in adulthood: a cohort study of European American subjects fed infant formula. Circulation 111, 1897-1903.

14. Stettler N, Bovet P, Shamlaye H, et al. (2002) Prevalence and risk factors for overweight and obesity in children from Seychelles, a country in rapid transition: the importance of early growth. Int J Obes Relat Metab Disord 26, 214-219.

15. Leunissen RW, Kerkhof GF, Stijnen T, et al. (2009) Timing and tempo of first-year rapid growth in relation to cardiovascular and metabolic risk profile in early adulthood. JAMA 301, 2234-2242.

16. Jaddoe VW, Bakker R, van Duijn CM, et al. (2007) The Generation R Study Biobank: a resource for epidemiological studies in children and their parents. Eur J Epidemiol 22, 917-923.

17. Jaddoe VW, van Duijn CM, van der Heijden AJ, et al. (2010) The Generation R Study: design and cohort update 2010. Eur J Epidemiol 25, 823-841.

18. Fredriks AM, van Buuren S, Wit JM, et al. (2000) Body index measurements in 1996-7 compared with 1980. Arch Dis Child. 82, 107-112.

19. Centraal Bureau voor de Statistiek (2004) Allochtonen in Nederland 2004 (Immigrants in the Netherlands 2004). Voorburg/Heerlen: Statistics Netherlands.
20. Statistics Netherlands (2004) Standaard onderwijsindeling 2003 (Standard Education Classification 2003). Voorburg/ Heerlen: Statistics Netherlands.

21. Nohr EA, Frydenberg M, Henriksen TB, et al. (2006) Does low participation in cohort studies induce bias? Epidemiology 17, 413-418.

22. Li R, Scanlon KS \& Serdula MK (2005) The validity and reliability of maternal recall of breastfeeding practice. Nutr Rev 63, 103-110.

23. Cupul-Uicab LA, Gladen BC, Hernández-Avila M, et al. (2009) Reliability of reported breastfeeding duration among reproductive-aged women from Mexico. Matern Child Nutr 5, 125-137.

24. Hebebrand J (1999) Breast feeding and obesity. Prolonging breast feeding to reduce obesity may be a burden. $B M J$ 319, 1576.

25. Butte NF (2001) The role of breastfeeding in obesity. Pediatr Clin North Am 48, 189-198.

26. Gillman MW (2002) Comment on: breast-feeding and obesity. J Pediatr 141, 749-750.

27. van Rossem L, Vogel I, Steegers E, et al. (2009) Breastfeeding patterns among ethic minorities: the generation $\mathrm{R}$ study. J Epidemiol Community Health 64, 1080-1085.

28. van Rossem L, Oenema A, Steegers EA, et al. (2009) Are starting and continuing breastfeeding related to educational background? The generation $\mathrm{R}$ study. Pediatrics 123, e1017-e1027.

29. Nommsen-Rivers LA \& Dewey KG (2009) Growth of breastfed infants. Breastfeed Med 4, 45-49.

30. Victora CG, Morris SS, Barros FC, et al. (1998) The NCHS reference and the growth of breast- and bottle-fed infants. J Nutr 128, 1134-1138.

31. Atladottir H \& Thorsdottir I (2000) Energy intake and growth of infants in Iceland - a population with high frequency of breast-feeding and high birth weight. Eur J Clin Nutr $\mathbf{5 4}$ 695-701.

32. Nielsen GA, Thomsen BL \& Michaelsen KF (1998) Influence of breastfeeding and complementary food on growth between 5 and 10 months. Acta Paediatr 87, 911-917.

33. Michaelsen KF, Petersen S, Greisen G, et al. (1994) Weight, length, head circumference, and growth velocity in a longitudinal study of Danish infants. Dan Med Bull 41, 577-585.

34. Gunnarsdottir I, Schack-Nielsen L, Michaelsen KF, et al. (2010) Infant weight gain, duration of exclusive breast-feeding and childhood BMI - two similar follow-up cohorts. Public Health Nutr 13, 201-207.

35. Michels KB, Willett WC, Graubard BI, et al. (2007) A longitudinal study of infant feeding and obesity throughout life course. Int J Obes (Lond) 31, 1078-1085.

36. Fuiano N, Rapa A, Monzani A, et al. (2008) Prevalence and risk factors for overweight and obesity in a population of Italian schoolchildren: a longitudinal study. J Endocrinol Invest 31, 979-984.

37. Hediger ML, Overpeck MD, Kuczmarski RJ, et al. (2001) Association between infant breastfeeding and overweight in young children. JAMA 285, 2453-2460.

38. Owen CG, Martin RM, Whincup PH, et al. (2005) The effect of breastfeeding on mean BMI throughout life: a quantitative review of published and unpublished observational evidence. Am J Clin Nutr 82, 1298-1307.

39. Ong KK, Ahmed ML, Emmett PM, et al. (2000) Association between postnatal catch-up growth and obesity in childhood: prospective cohort study. BMJ 320, 967-971. 